\title{
Mössbauer Spectroscopic Studies of Molecule-Based Magnets: Two-Dimensional Complexes Derived from Metal Schiff-Bases and Hexacyanoferrate(III)
}

\author{
S. Iijima, F. Mizutani, H. Miyasaka ${ }^{\mathrm{a}, *}$, N. Matsumoto ${ }^{\mathrm{b}}$, and H. Ōkawa ${ }^{\mathrm{a}}$ \\ National Institute of Advanced Industrial Science and Technology, \\ Tsukuba Central 6, Tsukuba, Ibaraki 305-8566, Japan \\ ${ }^{a}$ Department of Chemistry, Faculty of Science, Kyushu University, \\ Hakozaki, Higashi-ku, Fukuoka 812-8581, Japan \\ b Department of Chemistry, Faculty of Science, Kumamoto University, \\ Kurokami, Kumamoto 860-8555, Japan \\ * Current address: Department of Chemistry, Faculty of Science, Tokyo Metropolitan University, \\ Hachioji, Tokyo 192-0397, Japan \\ Reprint requests to Dr. S. I.; E-mail: s.iijima@aist.go.jp
}

Z. Naturforsch. 57 a, 603-606 (2002); received January 18, 2002

Presented at the XVIth International Symposium on Nuclear Quadrupole Interactions, Hiroshima, Japan, September 9-14, 2001.

Variable-temperature ${ }^{57} \mathrm{Fe}$ Mössbauer measurements on cyanide-bridged 2-D bimetallic assemblies $\mathrm{NEt}_{4}[\mathrm{Mn}(\text { salen })]_{2}\left[\mathrm{Fe}(\mathrm{CN})_{6}\right]$ (1), $\mathrm{K}[\mathrm{Mn}(3-\mathrm{MeOsalen})]_{2}\left[\mathrm{Fe}(\mathrm{CN})_{6}\right]$ (2) and $\mathrm{K}[\mathrm{Mn}(3-$ MeOsalen) $]_{2}\left[\mathrm{Fe}(\mathrm{CN})_{6}\right] \cdot 2 \mathrm{DMF}(\mathbf{3})$, where salen ${ }^{2-}=N, N^{\prime}$-ethylenebis(salicylidene iminato) dianion, revealed that these compounds exhibit a long range magnetic ordering below ca. $10 \mathrm{~K}$ under zero applied field. The quadrupole splittings of $\mathbf{1}-\mathbf{3}$ showed intermediate values between those of typical cyano-bridged 1-D and 3-D complexes. The paramagnetic state of $\mathrm{K}[\mathrm{Mn}(5-\mathrm{Cls} \text { len })]_{2}$ $\left[\mathrm{Fe}(\mathrm{CN})_{6}\right] \cdot 4 \mathrm{H}_{2} \mathrm{O}(4)$ turned to a bulk magnetic one with desolvation.

Key words: ${ }^{57} \mathrm{Fe}$ Mössbauer Spectroscopy; Schiff Bases; Hexacyanoferrate(III); Magnetic Ordering; Solvatomagnetism.

\section{Introduction}

In the past decade, spectacular advances have been undergone in the field of molecular magnetism [1]. An important approach to provide molecule-based materials exhibiting spontaneous magnetization is to construct ordered extended structures of paramagnetic metal centers [2]. Hexacyanometalate ions $\left[\mathrm{M}(\mathrm{CN})_{6}\right]^{x-}$ are known to be good building blocks for this purpose $[2-15]$. When $\left[\mathrm{M}(\mathrm{CN})_{6}\right]^{x-}$ reacts with simple metal ions, so-called "Prussian blue" analogues with 3-D structures of cubic lattice are formed [3 - 5]. Cationic metal-complex species, consisting of a metal ion and one or several organic ligands, also can be employed for the reaction with $\left[\mathrm{M}(\mathrm{CN})_{6}\right]^{x-}$ to construct bimetallic assemblies which are of interest from the view points of the variety of the di- mensionality and the possible tuning of the magnetic properties by changing the ligand's chemical structure [2, 6 - 15]. Recently, Miyasaka et al. reported the syntheses and cryomagnetic properties of a series of bimetallic compounds derived from the reaction between $[\mathrm{M}(\mathrm{SB})]^{+}$and $\left[\mathrm{Fe}(\mathrm{CN})_{6}\right]^{3-}$ of $1-\mathrm{D}, 2-\mathrm{D}$ and discrete structures $(\mathrm{SB}=$ quadridentate Schiff base) [6 - 11]. In order to get further information about the electronic and magnetic structure of this assembly system, we have measured ${ }^{57} \mathrm{Fe}$ Mössbauer spectra of three 2-D network compounds $\mathrm{NEt}_{4}[\mathrm{Mn}(\text { salen })]_{2}$ $\left[\mathrm{Fe}(\mathrm{CN})_{6}\right]$ (1), $\mathrm{K}[\mathrm{Mn}(3-\mathrm{MeOsalen})]_{2}\left[\mathrm{Fe}(\mathrm{CN})_{6}\right]$ (2) and $\mathrm{K}[\mathrm{Mn}(3-\mathrm{MeOsalen})]_{2}\left[\mathrm{Fe}(\mathrm{CN})_{6}\right] \cdot 2 \mathrm{DMF}(\mathbf{3})$, and the related discrete trinuclear compound $\mathrm{K}[\mathrm{Mn}(5 \text {-Clsalen })]_{2}\left[\mathrm{Fe}(\mathrm{CN})_{6}\right] \cdot 4 \mathrm{H}_{2} \mathrm{O}$ (4), where salen $^{2-}=N, N^{\prime}$-ethylenebis(salicylidene iminato) dianion. 
Table 1. Mössbauer parameters.

\begin{tabular}{ccccc}
\hline Compound & Temp./K & $\delta / \mathrm{mm} \cdot \mathrm{s}^{-1}$ & $\Delta E_{Q} \mathrm{a} / \mathrm{mm} \cdot \mathrm{s}^{-1}$ & $H_{\mathrm{n}} / \mathrm{kOe}$ \\
\hline $\mathbf{1}^{\mathrm{b}}$ & 298 & -0.13 & 1.06 & \\
& 78 & -0.05 & 1.30 & \\
$\mathbf{2}$ & 4.2 & -0.03 & 1.43 & 127 \\
& 298 & -0.09 & 1.40 & \\
$\mathbf{3}$ & 78 & -0.07 & 1.70 & \\
& 4.2 & -0.05 & 1.87 & 119 \\
& 298 & -0.10 & 0.68 & \\
$\mathbf{4}$ & 78 & -0.08 & 1.12 & \\
& 4.2 & -0.06 & 1.26 & 115 \\
Desolvated $\mathbf{4}$ & 298 & -0.13 & 1.45 & \\
& 4.2 & -0.05 & 1.81 & \\
& 298 & -0.15 & 1.43 & \\
\hline
\end{tabular}

${ }^{\mathrm{a}}$ The sign of $V_{z z}$ was not determined. ${ }^{\mathrm{b}}$ For example, the analysis of the spectrum of $\mathbf{1}$ at $4.2 \mathrm{~K}$ gives the other following parameters: $\eta=0.5-1.0,\left|\frac{1}{2} e V_{z z} Q\right|=1.37-1.23 \mathrm{~mm} / \mathrm{s}$, $\Theta=52^{\circ}, \varphi=10^{\circ}$, on the assumption of $V_{z z}>0 ; \eta=0.1$ $1.0,\left|\frac{1}{2} e V_{z z} Q\right|=1.43-1.23 \mathrm{~mm} / \mathrm{s}, \Theta=71-82^{\circ}, \varphi=25-$ $40^{\circ}$, on the assumption of $V_{z z}<0$. Here, the symbols have the usual meanings [19].

\section{Experimental}

The compounds $\mathbf{1}$ - $\mathbf{4}$ were prepared according to procedures previously reported [7, 11]. The Mössbauer spectra were measured between 4.2 and $298 \mathrm{~K}$ by using a ${ }^{57} \mathrm{Co}(\mathrm{Rh})$ source moving in a constant acceleration mode. The isomer shifts are reported relative to metallic iron foil. The samples were sealed in containers consisting of a $\mathrm{Cu}$ block and $\mathrm{My}-$ lar films for the measurements.

\section{Results and Discussion}

Compounds $\mathbf{1}$ and $\mathbf{2}$ were reported to have similar crystal structures $[7,11]$. In each compound, two $\mathrm{CN}^{-}$ groups of the $\left[\mathrm{Fe}(\mathrm{CN})_{6}\right]^{3-}$ moiety bridge two $\mathrm{Mn}$ ions to give a linear bridging mode of (SB)Mn-NC-Fe-CN$\mathrm{Mn}(\mathrm{SB})$. Two other $\mathrm{CN}^{-}$groups of the $\left[\mathrm{Fe}(\mathrm{CN})_{6}\right]^{3-}$ moiety are bound to the adjacent chains, producing a two-dimensional network structure in which a net unit has a cyclic octamer structure [-Mn-NC-Fe-CN]$_{4}$. The counter anions $\left(\mathrm{NEt}_{4}{ }^{+}\right.$or $\left.\mathrm{K}^{+}\right)$are sandwiched between the network layers. Cryomagnetic measurements indicated that an intralayer antiferomagnetic interaction operates between the $\mathrm{Mn}(\mathrm{III})$ and the Fe(III) ions in $\mathbf{1}$, and that the compound orders ferrimagnetically below the critical temperature, $T_{\mathrm{c}}=7.7 \mathrm{~K}$ [11]. As for $\mathbf{2}$, intralayer ferromagnetic and interlayer antiferromagnetic interactions were observed, and $\mathbf{2}$ be-

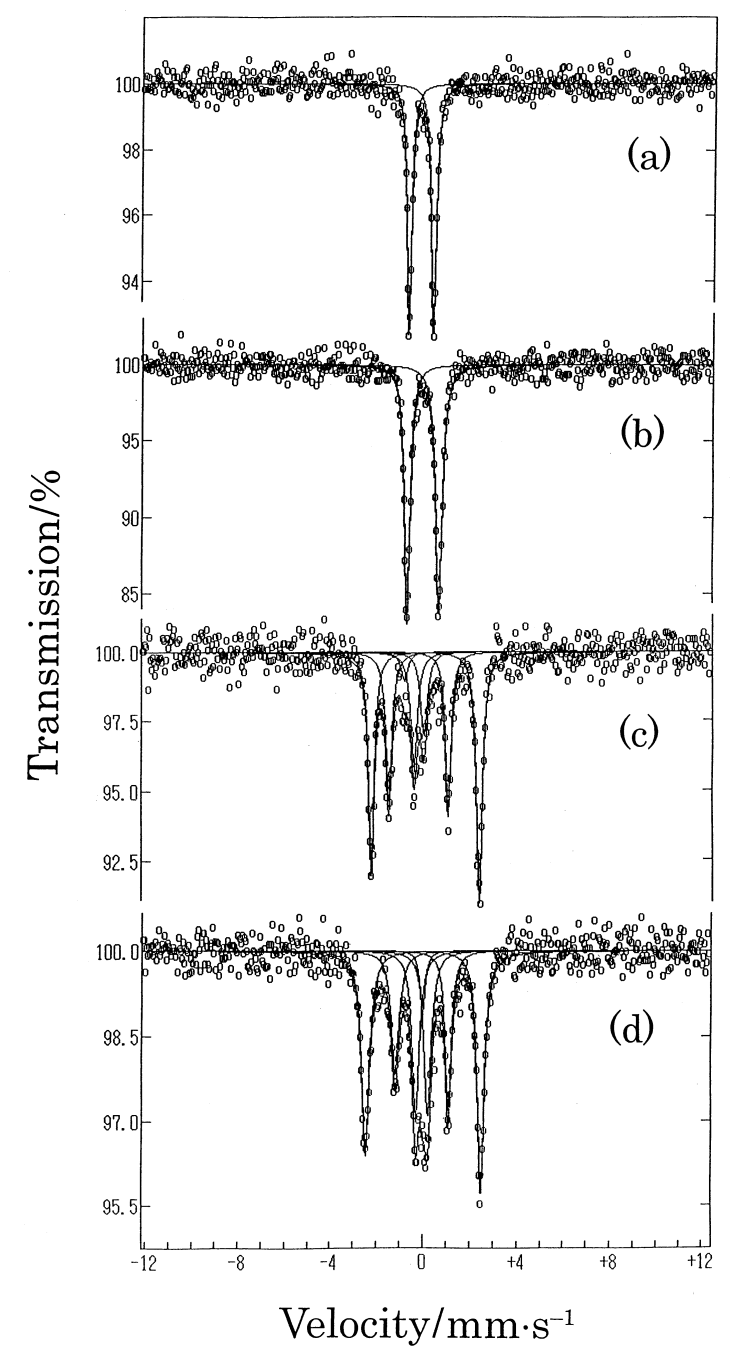

Fig. 1. ${ }^{57} \mathrm{Fe}$ Mössbauer spectra of $\mathrm{NEt}_{4}[\mathrm{Mn}(\text { salen })]_{2}$ $\left[\mathrm{Fe}(\mathrm{CN})_{6}\right]$ (1) at (a) $298 \mathrm{~K}$, (b) $10 \mathrm{~K}$, and (c) $4.2 \mathrm{~K}$, and (d) ${ }^{57} \mathrm{Fe}$ Mössbauer spectrum of $\mathrm{K}[\mathrm{Mn}(3-\mathrm{MeOsalen})]_{2}$ $\left[\mathrm{Fe}(\mathrm{CN})_{6}\right](2)$ at $4.2 \mathrm{~K}$.

haves as a metamagnet with variable $T_{\mathrm{c}}(\mathrm{ca} .8-10 \mathrm{~K}$ ) depending on the applied field [7].

Selected Mössbauer spectra of $\mathbf{1}$ and $\mathbf{2}$ are shown in Fig. 1, and their Mössbauer parameters are listed in Table 1 along with those of the other compounds mentioned below. Compound 1 gave a single quadrupole doublet above $10 \mathrm{~K}$, showing an ordinary paramagnetism of $\mathrm{Fe}(\mathrm{III})$ (Figs. 1a, b). The low isomer shift, $\delta(\sim 0.0 \mathrm{~mm} / \mathrm{s})$, and the temperature-dependent quadrupole splitting, $\Delta E_{Q}$, observed were characteristic of a low-spin Fe(III) state [16], which is known to be a common spin state of Fe(III) in vari- 


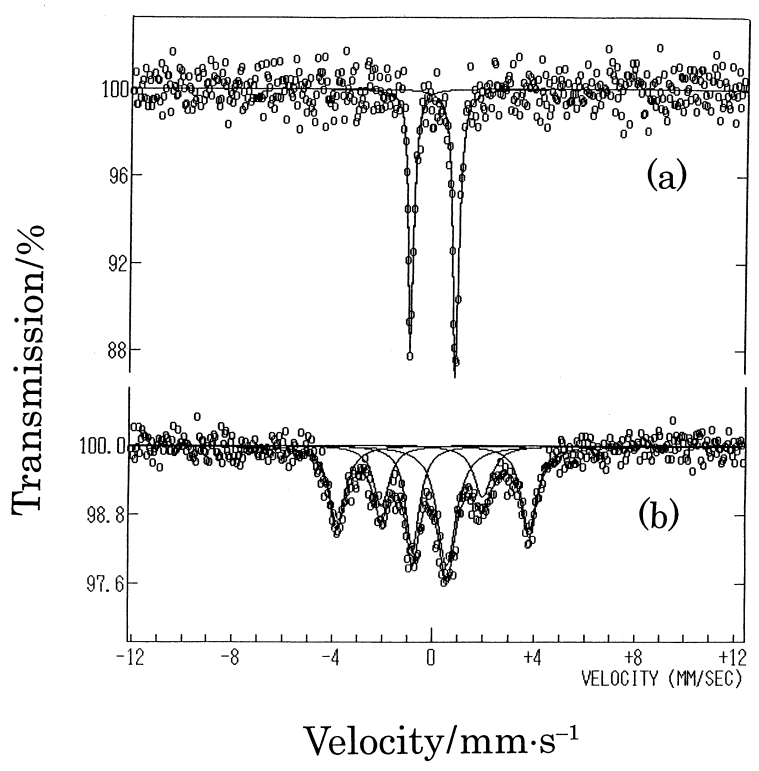

Fig. 2. ${ }^{57} \mathrm{Fe}$ Mössbauer spectra at $4.2 \mathrm{~K}$ of (a) $\mathrm{K}[\mathrm{Mn}(5-$ Clsalen) $]_{2}\left[\mathrm{Fe}(\mathrm{CN})_{6}\right] \cdot 4 \mathrm{H}_{2} \mathrm{O}(4)$ and (b) desolvated 4.

ous $\left[\mathrm{Fe}(\mathrm{CN})_{6}\right]^{3-}$ complexes $[2-15]$. On lowering the temperature to $8 \mathrm{~K}$, a line-broadening began to appear in the spectrum of $\mathbf{1}$, and at $4.2 \mathrm{~K}$, a sharp Mössbauer septet was observed as shown in Fig. 1c. This sudden change of the line-shape of a Mössbauer spectrum in a narrow temperature range evidences long range magnetic ordering below ca. $8 \mathrm{~K}$, under zero applied field. The temperature-dependence of the spectrum shape of $\mathbf{2}$ was very similar to that of $\mathbf{1}$, also gaving a wellresolved septet at $4.2 \mathrm{~K}$ (Fig. 1d). While the previous cryomagnetic results for $\mathbf{2}$ showed some complexity (due to metamagnetism) [7], this Mössbauer behavior clearly indicated the bulk magnetic ordering of $\mathbf{2}$ at low temperatures.

The $\Delta E_{Q}$ values of compounds $\mathbf{1}$ and $\mathbf{2}$ (for example, 1.30 and $1.70 \mathrm{~mm} / \mathrm{s}$ at $78 \mathrm{~K}$, respectively) were larger than those of the $\left[\mathrm{Fe}(\mathrm{CN})_{6}\right]^{3-}$ anions in Prussian blue analogues ranging ca. between 0.2 and $1.0 \mathrm{~mm} / \mathrm{s}$ around and below liquid nitrogen temperature $(77.3 \mathrm{~K})$ [17]. This would reflect the low-dimensionality (2-D structure) of these compounds, resulting in a considerable deviation of the $\left[\mathrm{Fe}(\mathrm{CN})_{6}\right]^{3-}$ unit from cubic symmetry, as seen in the X-ray crystallographic data of $\mathbf{1}$ [11]. (The exact crystal structure of 2 is not known [7].) As for the 1-D cyano-bridged complexes, $\Delta E_{Q}$ values $>2.0 \mathrm{~mm} / \mathrm{s}$ were sometimes obtained; for examples, $2.44 \mathrm{~mm} / \mathrm{s}$ at $78 \mathrm{~K}$ for $[\mathrm{Mn}($ cyclam $)]\left[\mathrm{Fe}(\mathrm{CN})_{6}\right] \cdot 3 \mathrm{H}_{2} \mathrm{O}$ [15] and $2.56 \mathrm{~mm} / \mathrm{s}$ at $78 \mathrm{~K}$ for $\left\{\left[\mathrm{Eu}(\text { phen })_{2}\left(\mathrm{H}_{2} \mathrm{O}\right)_{2}\right]-\right.$ $\left[\mathrm{Fe}(\mathrm{CN})_{6}\right] \cdot 2$ phen $\}_{x}[18]$, where cyclam $=1,4,8,11$ tetraazacyclotetradecane and phen $=1,10$-phenanthroline. The magnitudes of the internal magnetic field $\left(H_{\mathrm{n}}\right)$ were estimated [19] to be 127 and $119 \mathrm{kOe}$ for $\mathbf{1}$ and $\mathbf{2}$, respectively. They are very close to the spinpolarized Hartree-Fock estimation (125 kOe) [20]. On the other hand, much larger $H_{\mathrm{n}}$ values were reported for the $\left[\mathrm{Fe}(\mathrm{CN})_{6}\right]^{3-}$ in Prussian blue analogues (160 - $270 \mathrm{kOe})$, and the deviation from the calculated value was ascribed to a large delocalization of $3 \mathrm{~d}$ electrons via back donation [3], which would be insignificant in the present compounds containing metal-complex cations. The smaller $\Delta E_{Q}$ value $(1.12 \mathrm{~mm} / \mathrm{s}$ at $78 \mathrm{~K})$ of 3 than that of 2 suggests that the inclusion of DMF molecules in the crystal lattice of $\mathbf{2}$ decreases the extent of distortion of the $\left[\mathrm{Fe}(\mathrm{CN})_{6}\right]^{3-}$ anion. No substantial difference in the magnetic-splitting behavior was observed between 2 and 3.

Compound 4 was reported to be a discrete trinuclear compound with linear Mn-NC-Fe-CN-Mn linkage, and to act as a paramagnet at least above 4.2 K [7]. The Mössbauer spectrum of 4 consisted of a quadrupole doublet even at $4.2 \mathrm{~K}$ (Fig. 2a), in accord with the cryomagnetic result. After the compound was heated at $40^{\circ} \mathrm{C}$ under a pressure of $10^{-4} \mathrm{~Pa}$ for $24 \mathrm{~h}$, it gave a quite different spectrum at the same temperature, as seen in Fig. 2b, which indicates the occurrence of bulk magnetic ordering. Elemental analyses roughly showed the loss of two water molecules from 4 by the heat treatment. Similarly to the case of the $\mathrm{NEt}_{4}$ analogue of 4 [8], an extended structure formation by desolvation seems to occur in the crystal lattice of 4. However, the broadened spectral feature suggested that the structure of desolvated $\mathbf{4}$ is not uniform, and the $H_{\mathrm{n}}$ value was significantly different from those of $\mathbf{1}$ - 3. By the re-wetting of desolvated 4 , its spectrum at $4.2 \mathrm{~K}$ reverted to a quadrupole doublet. Another kind of "solvatomagnetism", where desolvation causes a transition from a bulk magnetic state to a paramagnetic one, is currently being investigated for $\left[\mathrm{Fe}(\right.$ salen $\left.)\left(\mathrm{CH}_{3} \mathrm{OH}\right)_{2}\right][\mathrm{Fe}(\text { salen })]_{2}\left[\mathrm{Fe}(\mathrm{CN})_{6}\right] \cdot 3 \mathrm{H}_{2} \mathrm{O}$ [11] by ${ }^{57} \mathrm{Fe}$ Mössbauer spectroscopy. 
[1] O. Kahn, Advances in Inorganic Chemistry; Academic Press, Inc., San Diego 1995, Vol. 43, p. 179.

[2] H. Ōkawa and M. Ohba, In Molecule-Based Magnetic Materials: Theory, Techniques, and Applications; M. M. Turnbull, T. Sugimoto, and L. K. Tompson, Eds., ACS Symposium Series 644, American Chemical Society, Washington, DC 1996, p. 319.

[3] A. Z. Hrynkiwicz, B. D. Sawicka, and J. A. Sawicki, Acta Phys. Pol. A37, 811 (1970).

[4] S. Ferlay, T. Mallah, R. Ouahès, P. Veillet, and M. Verdauguer, Nature (London) 378, 701 (1995).

[5] S. Ohkoshi, T. Iyoda, A. Fujishima, and K. Hashimoto, Phys. Rev. B 56, 11642 (1997).

[6] H. Miyasaka, N. Matsumoto, H. Ōkawa, N. Re, E. Gallo, and C. Floriani, Angew. Chem. Int. Ed. 34, 1446 (1995).

[7] H. Miyasaka, N. Matsumoto, H. Ōkawa, N. Re, E. Gallo, and C. Floriani, J. Amer. Chem. Soc. 118, 981 (1996).

[8] H. Miyasaka, N. Matsumoto, N. Re, E. Gallo, and C. Floriani, Inorg. Chem. 36, 670 (1997)

[9] H. Miyasaka, H. Ieda, N. Matsumoto, N. Re, E. Gallo, and C. Floriani, Inorg. Chem. 37, 255 (1998).
[10] H. Miyasaka, H. Ōkawa, A. Miyazaki, and T. Enoki, J. Chem. Soc. Dalton Trans. 3991 (1998).

[11] H. Miyasaka, Dissertation, Kyushu Univ. 1998.

[12] M. S. E. Fallah, E. Rentshler, A. Caneschi, R. Sessoli, and D. Gatteschi, Angew. Chem. Int. Ed. 35, 1947 (1996).

[13] E. Colacio, J. M. Domíngues-Vera, M. Ghazi, R. Kivekäs, F. Lloret, J. M. Moreno, and H. Stoeckli-Evans, Chem. Commun. 987 (1999).

[14] B. Nowicka, M. Hagiwara, Y. Wakatsuki, and H. Kisch, Bull. Chem. Soc. Japan 72, 441 (1999).

[15] S. Iijima, Z. Honda, S. Koner, and F. Mizutani, J. Magn. Magn. Mater. 223, 16 (2001).

[16] H. Sano and M. Katada, Mössbauer Spectroscopy, Principles and Applications, Gakkai Shuppan Center, Tokyo 1996, p. 74.

[17] A. Z. Hrynkiwicz, B. D. Sawicka, and J. A. Sawicki, Phys. Stat. Sol. 38, K111 (1970).

[18] M. Katada, private communication.

[19] S. V. Karyagin, Sov. Phys. Solid State 8, 391 (1966).

[20] R. E. Watson and A. J. Freeman, Phys. Rev. 123, 2027 (1961). 